\title{
Development of Hybridized Completions for Extended Reach Horizontal Wells
}

\author{
Bisweswar Ghosh*, Omar Jamal Chammout, Mohamad Yousef Alklih, Samuel Osisanya \\ Petroleum Engineering Department, Khalifa University of Science \& Technology, Abu Dhabi, United Arab Emirates \\ Email address: \\ bisweswar.ghosh@ku.ac.ae (B. Ghosh), omarjchammout@gmail.com(O. J. Chammout), malklih@gmail.com (M. Y. Alklih), \\ sosisanya@ku.ac.ae (S. Osisanya) \\ ${ }^{*}$ Corresponding author
}

\section{To cite this article:}

Bisweswar Ghosh, Omar Jamal Chammout, Mohamad Yousef Alklih, Samuel Osisanya. Development of Hybridized Completions for Extended Reach Horizontal Wells. Petroleum Science and Engineering. Vol. 4, No. 1, 2020, pp. 1-15. doi: 10.11648/j.pse.20200401.11

Received: December 26, 2019; Accepted: January 9, 2020; Published: February 10, 2020

\begin{abstract}
Non-uniform production and injection profiles in extended reach horizontal wells invite several production and recovery issues. Downhole flow control devices, along with dynamic reservoir modeling, have been beneficial in regulating flow, improving productivity from the toe section, delaying water breakthrough, reducing water coning, and improving overall reservoir sweep. However, such measures add to substantial completion costs and may not be economical for marginal reservoirs. Using simple slotted liners is a cheaper option but may not be effective in regulating injection/production profiles in the longer term. This research focused on applying "coupled static and dynamic modeling" to examine and compare five different types of completion designs, using data from a heterogeneous carbonate reservoir. Results show that inflow control device (ICD) integrated completions can achieve better recovery than the slotted, pre-perforated, or engineered liners. Engineered-slotted liners perform better than the pre-perforated-slotted liners. The pre-perforated-slotted liners do not show much improvement over open-hole completions. Finally, a hybrid completion design is optimized by combining ICD with engineered-slotted liners, which showed higher well productivity, lower water cut production, and reduced completion cost.
\end{abstract}

Keywords: Horizontal Well Completion, Inflow Control Devices, Limited Entry Liners, Production Optimization, Water Control

\section{Introduction}

Due to several advantages over vertical wells, horizontal well drilling technology has grown rapidly since the late 1980 s, and with the advancement of cutting edge technologies, the horizontal reservoir contact lengths have been extended significantly [1]. Extended Reach Drillings (ERD) with measured depth (MD) of 40,320 ft and horizontal section of $35,770 \mathrm{ft}$ in Al-Shaheen field, located in Qatar offshore and $41,667 \mathrm{ft}$ long with a horizontal section of 38,514 ft. in Sakhalin, Russia [2] are some of the examples of modern days drilling trends. Well completion tools and techniques have also been developed at an equal pace for better well control and productivity. Many potential advantages associated with horizontal wells are higher well productivity, enhanced sweep efficiency, and delayed water and gas coning, all due to increased wellbore-reservoir contact area and reduced drawdown pressure [3]. Despite the advantages of drilling
ERD wells, they are associated with unprecedented challenges in the areas of drilling and completion and the complex wellbore fluid dynamics. Production from conventional well can be controlled at the surface by manipulating the wellhead choke to control high water or gas cut production. This technique is no longer sufficient in ERD wells because having extended contact between the wellbore and the reservoir does not permit uniform drainage; often resulting in premature breakthrough of unwanted fluids (gas and/or water) This is frequently evidenced in a water drive reservoir, where water coning in horizontal well occurs early on resulting in high water cut production, negatively impacting economics [4]. Chammout et al. [5] have summarized the major issues with extended reach horizontal wells as:

1. Heel-toe-effect resulting from frictional pressure losses

2. Permeability heterogeneity along the horizontal section.

3. The distance of the gas/water contact zone from the wellbore, which may vary due to the well geometry and 
shape of the gas/water cone.

4. Well pressure variation resulting from penetration of several pressure regions of the reservoir.

5. Irregular profile of injected water and gas due to permeability heterogeneity.

The heel-toe-effect is the result of the frictional pressure drop along the wellbore. The impact of heel-toe effect becomes pronounced as the horizontal length increases [6]. The frictional pressure loss can reach the threshold drawdown pressure in high flow rate ERD wells, resulting in low or no production form the toe section. Thus in high permeability reservoir, it would be wiser to drill a larger diameter well with shorter laterals [7].

Proven and practical solutions to the above challenges were addressed collectively, which resulted in smart completions. The downhole inflows and outflows were controlled by various devices incorporated during initial well completion, with the objective to control the flow to or from the heterogeneous sections [8]. The distribution and setting of the flow controllers are carefully designed to improve the areal and vertical sweep efficiency by establishing a stable flood front around the wellbore and hence preventing unwanted fluid production [9.10]. Two major categories of smart completion devices used are Internal Control Valves (ICV) and Inflow Control Devices (ICD) [9]. To design an effective smart completion, it is essential to perform dynamic reservoir simulation to demonstrate the potential benefits in both injectors and producers. Employing a smart completion design to balance the influx of a producer well or the outflow of an injector well provides tangible benefits in terms of delayed water breakthrough, increased production rate, optimized injection rate, and eventually increased recovery $[11,12]$. Despite these benefits, economics may not permit smart completions in many situations, and simpler completions such as slotted liner with external casing packers may be enough in controlling the flow profile of produced or injection fluids. Another solution that could be even more attractive in terms of technology and cost-effectiveness is the engineered slotted liner or the Limited-Entry Liner (LEL). The LEL can compensate for the variation in reservoir permeability across the long horizontal section by varying both the density and the size of the openings (slots) within the liner [13, 14]. Operating companies usually develop a very generic LEL completion model without much considerations of the reservoir heterogeneities. This is because of the fact that their core objective was to design the LEL to facilitate in running the coiled tubing all the way to the toe end for a uniform fluid outflow when a stimulation job by bull-heading was considered.

The present work was targeted to overcome the listed challenges of completion design in ERD wells. In this work reservoir and pilot well data from a Middle-East offshore field are used. Five types of completion scenarios are investigated for the reservoir contact portion of the wells through a coupled simulation technique. The results were analyzed in order to arrive at the optimum completion design taking into account technical and economic advantages. The five scenarios considered were:

6. Open-hole barefoot completion.

7. Pre-Perforated Liner (PPL) completion.

8. Engineering Limited Entry Liner (LEL) completion.

9. Inflow Control Device (IC)-Integral completion.

10. ICD-LEL hybrid completion.

For each of the scenarios, except for the open-hole, five sensitivity cases are run to determine the optimum case for that particular scenario. In addition, the novel outcome of this work is designing a hybridized completion (ICD-LEL combination) utilizing the best of the ICD-integrated design and the LEL that is meant to optimize the oil recovery.

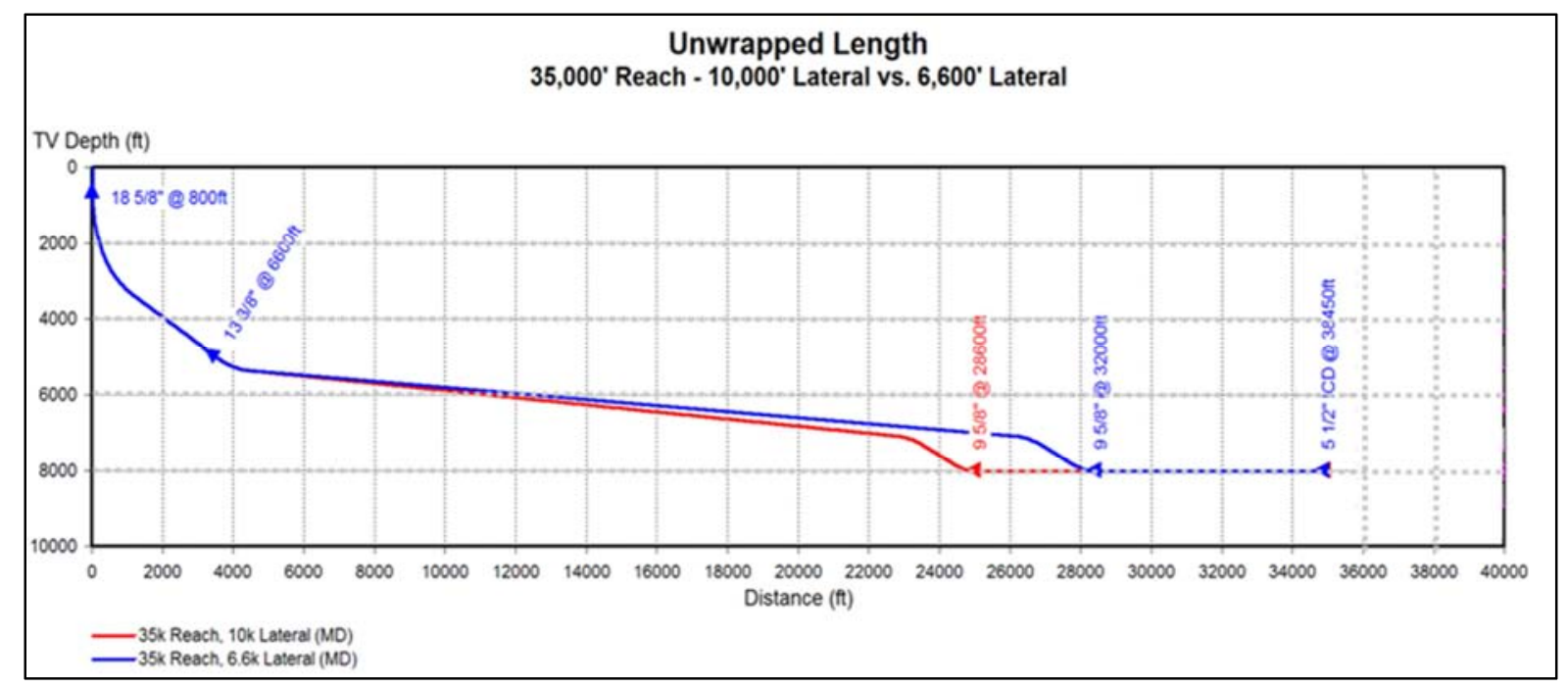

Figure 1. MRC pilot well design.

\section{Methodology}

This section includes a description of the workflow and methodology adopted in this study, including; (1) weighing different completion options (2) technical and economic evaluation of the different well completion options, and (3) selecting the optimum completion option. 


\subsection{Well Description}

An extended reach drilled well is one where the step-out ratio (horizontal departure/tur vertical depth) is greater than 2.0. Figure 1 shows a typical trajectory of the target pilot well design. The production optimization analysis on the well length against the economics of drilling an ERD well shows how oil production rate for a barefoot completion varies with reservoir exposure (Figure 2). The optimum well length could

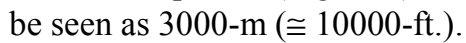

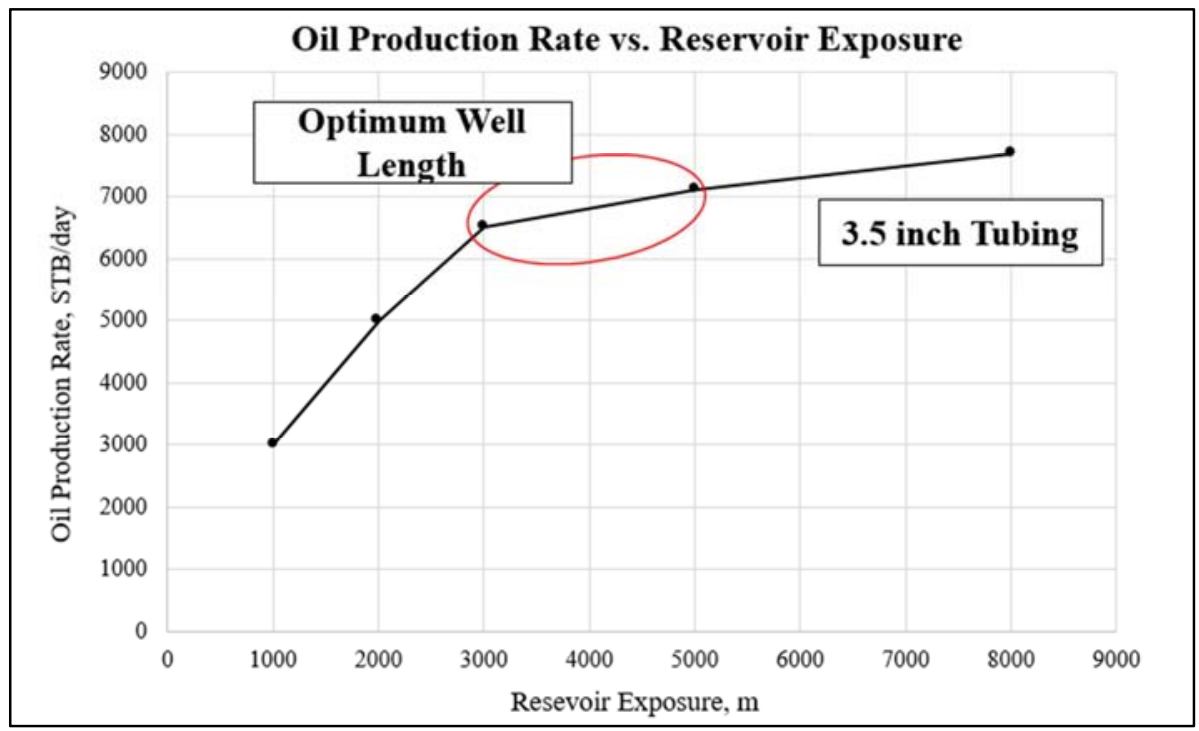

Figure 2. ERD optimal length is $3000 \mathrm{~m}$ (equivalent to 10,000 ft.).

\subsection{Completion Simulation}

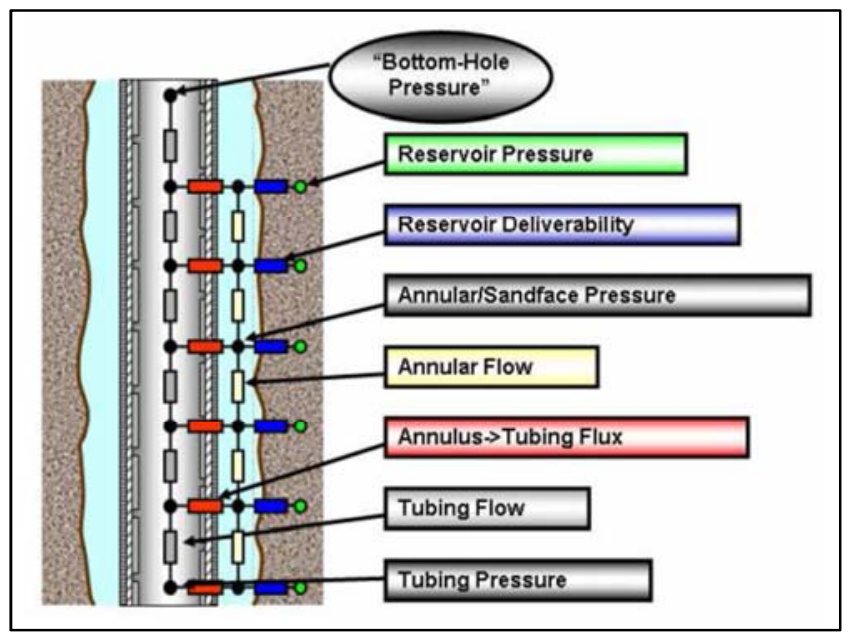

Figure 3. Schematic of the software network model [15].

The commercial simulator used for this work is a steady-state network-based numerical simulator that models multiphase fluid flow in the well and near wellbore region. Various completion hardware options are incorporated into the simulated well model, including open hole, slotted liner, limited entry liners, and ICDs. The software calculates overall production performance, inflow profile, pressure profile, and flow rates in tubing and annulus. It can also be used to calculate the expected skin values caused by the application of the different completion designs (Wang et al. 2008). The completion and the near-wellbore region are numerically represented by the distribution of nodes interconnected by flow channels. The completion specifications, fluids, and the reservoir properties define appropriate pressure drop correlations for each flow channel, whether in the formation, annulus, and tubing, or within a range of completion parts. Figure 3 shows the schematic of the software network model. The reservoir flow problem discussed in this study assumes an under-saturated reservoir (black-oil with water and gas). Both producer and injector are included in the sector model, but only a single producer is modeled for completion design.

\subsection{Reservoir Simulation}

For the dynamic flow modeling, another reservoir simulation software is utilized, which is conventionally used to simulate flow in a complex reservoir such as the one considered in this study. Typically, reservoir simulation employs two-node wells (one for the wellhead and one for the bottom hole) to describe well completions. Pressure drops due to friction and hydrostatics within the well are dealt with using hydraulic lift curves generated by node based simulators. Lift curves are usually generated for the mid-perforation depth when used with a 2-Node well model [16]. The reservoir and fluid properties applied in this study are as follows: reservoir pressure $(3800 \mathrm{psi})$, reservoir temperature $\left(210^{\circ} \mathrm{F}\right)$, and oil density $(0.79 \mathrm{~g} / \mathrm{cc})$.

\subsection{Coupling the Steady State and Dynamic Models}

The steady-state software is used to create a detailed model of the wellbore completion. The steady-state software is coupled with the dynamic software, thus leveraging on the capabilities of each software to make more accurate models. A coupled model dynamically captures the coupled effects of wellbore hydraulics and reservoir simulation, thus improving 
the accuracy of the simulation. The workflow model for the coupled simulator used specifically to optimize the design of the completion string.

\subsection{Coupled Modeling Workflow}

There are four main components that comprise the coupled model:

1. The steady-state completion model.

2. The dynamic reservoir model.

3. Hydraulics model.

4. Well management logic.

The coupling linkage is controlled through well management and based on the multi-node well configuration. The steps adopted for this workflow in order to conduct the sensitivity runs are:

1. Build the dynamic simulation.

2. Construct the well model.

3. Update hydraulics tables.

4. Place calls to the steady-state software in well management.

5. Run simulation.

The coupled software-models are embedded in the dynamic simulator and are invoked through Well Management logic and are based on the multi-node well configuration. The dynamic simulator provides the steady-state simulator with reservoir pressure, well productivity (in terms of an "R-value"), flowing phase fraction via phase mobility, $\mathrm{R}_{\mathrm{s}}$ value to calculate solution/free gas concentration, and well constraint (pressure or rate limit). The phase mobility is also captured when regions with different relative permeabilities are connected to the same well. The steady-state simulator provides the dynamic simulator with the hydraulics inside the wellbore via annulus pressures that are then used to calculate pressure changes along the well. The pressure changes are applied in the dynamic simulator via Controlled Pressure Change (CPC) conditions. This process is shown in Figure 4. In order for the coupling to work, property data are supposed to be preprocessed in the steady-state software in order to be consistent with the dynamic model. PVT data and fluid densities are copied from the dynamic model. Table 1 lists the data passed by the linkage, and Table 2 lists the data shared between the two software [17]. The works conducted during the workflow were as follows (for details, see Appendix A):

1. Modifying the reservoir model for coupling.

2. Converting the well to a multi-node well configuration.

3. Completion design.

4. Simulation region.

5. Segmenting.

6. Limitations of coupled simulation.

Table 1. Data passed between simulators by the linkage.

\begin{tabular}{lll}
\hline Simulator & Linkage & \\
\hline & & Well boundary condition \\
& Required & Reservoir pressure \\
& Phase mobility \\
Dynamic to Steady State & & Well productivity - R-value \\
& & Solubility Factor \\
& Additional feature & Saturation pressure - using multi bubble point option in NETool \\
& & Gas lift rate - using gas lift in the well \\
& Required & ICV (inflow control valve) settings - completion includes an ICV \\
& Additional feature & Well pressure (tubing or annulus) - CPC value \\
& Skin factor \\
& Optional; for diagnostic purposes only & Segment phase rate \\
& & Total phase rate \\
& & Total reservoir rate \\
\hline
\end{tabular}

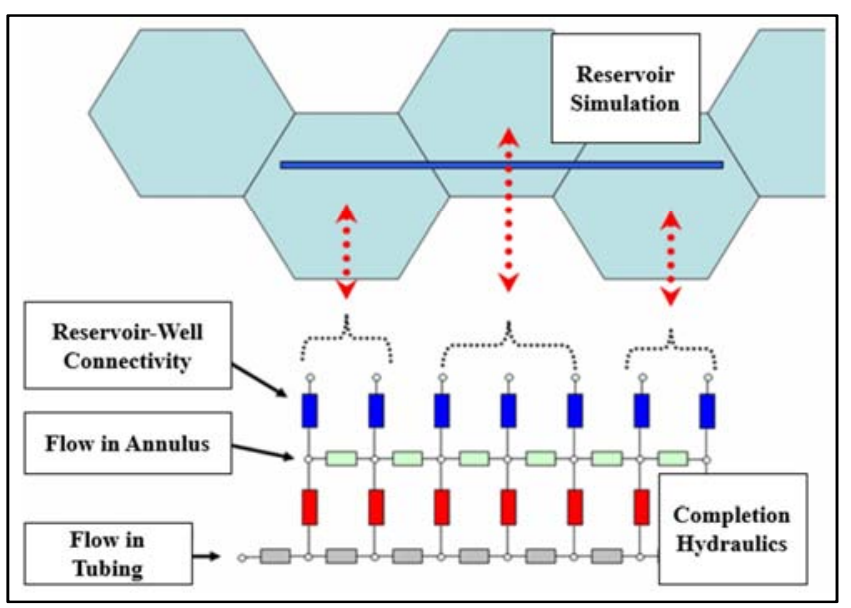

Figure 4. Schematic of the coupling of steady-state and dynamic simulators.
Table 2. Shared data between the simulators.

\begin{tabular}{ll}
\hline Data Type & Shared Data \\
\hline & PVT data \\
& Fluid density at standard conditions \\
& Reference pressure \\
Required & Water formation volume factor at reference pressure \\
& Water viscosity at reference pressure \\
& Water compressibility \\
& Water viscosity \\
& Hydraulic lift curves \\
Optional & Relative permeability data \\
\hline
\end{tabular}

\subsection{Model Description}

Different sensitivity completion parameters are performed over a 3-D sector model from the carbonate reservoir, which exhibits a heterogeneous behavior. It consists of a total of (140 $\times 140 \times 35) \mathrm{m}$ in the $\mathrm{X}, \mathrm{Y} \& \mathrm{Z}$ directions, respectively. In order to perform accurate modeling, local grid refinement has 
been applied near the producer with a grid size of $25 \mathrm{~m}$ in the $\mathrm{X}$ - and $\mathrm{Y}$ - directions. Away from the producer, the grid size is $50 \mathrm{~m}$ leading to a $100 \mathrm{~m}$ further in the water zone. Table 3 summarizes the geometrical and petrophysical properties of the layers of this sector model. In this sector model, two injectors are completed on both sides of the model, with one producer completed in the middle of the sector model arranged in a staggered line drive pattern. The spacing between the wells is set at about $1 \mathrm{~km}(3,280 \mathrm{ft}$.). The producer is completed from layer 33, while the injector is completed in the bottom layer number 35 . According to the reservoir and well potential experience, the liquid production rate was set to be $5000 \mathrm{STB} /$ day for the producer, while the water injection rate was specified to be constant at $2,500 \mathrm{STB} /$ day for each well totaling 5,000 STB/day.

The significance of the model is embedded in the wide variation of the petrophysical properties of its layers resulting in a heterogeneous and anisotropic system (Table 3 and Table 4). Horizontal permeability of the layers ranges from $0.01-$ $2000 \mathrm{mD}$, with an average reservoir permeability to be around $28 \mathrm{mD}$. One of the most crucial steps to the sensitivity analysis at this stage is to point out the great variation of permeability along the profile of the pilot well, especially towards the toe section.

Table 3. Geometrical and petrophysical properties of the layers.

\begin{tabular}{lll}
\hline Flow Unit & Permeability & Value \\
\hline 1 & Very High & $\mathrm{k}>1000$ \\
2 & High & $100<\mathrm{k}<1000$ \\
3 & Moderate & $10<\mathrm{k}<100$ \\
4 & Low & $1<\mathrm{k}<10$ \\
5 & Very Low & $\mathrm{k}<1$ \\
\hline
\end{tabular}

Table 4. More details on geometrical and petrophysical properties of the layers.

\begin{tabular}{llll}
\hline Compartment \# & $\begin{array}{l}\text { Length Across } \\
\text { the Lateral (ft.) }\end{array}$ & $\begin{array}{l}\text { Compartment } \\
\text { Length }\end{array}$ & $\begin{array}{l}\text { Flow } \\
\text { Unit }\end{array}$ \\
\hline 1 & $0-1500$ & 1500 & 3 \\
2 & $1500-2700$ & 1200 & 3 \\
3 & $2700-2900$ & 200 & 1 \\
4 & $2900-5100$ & 2200 & 3 \\
5 & $5100-5400$ & 300 & 3 \\
6 & $5400-5500$ & 100 & 1 \\
7 & $5500-5800$ & 300 & 3 \\
8 & $5800-6000$ & 200 & 1 \\
9 & $6000-6300$ & 300 & 3 \\
10 & $6300-6600$ & 300 & 1 \\
11 & $6600-6800$ & 200 & 1 \\
12 & $6800-7200$ & 400 & 2 \\
13 & $7200-7300$ & 100 & 4 \\
14 & $7300-8000$ & 700 & 3 \\
15 & $8000-9000$ & 100 & 4 \\
16 & $9000-T D$ & 842 & 4 \\
\hline
\end{tabular}

\subsection{Permeability Profiling}

In order to characterize the flow performance across the lateral and determine the number of compartments needed to obtain a uniform flow, the scheme presented in Table 3 and Table 4 is adopted to compartmentalize the lateral, resulting in dividing the lateral into 16 compartments. It can be noticed that 5 zones are underflow unit \#1, 1 zone underflow unit \#2, 7 zones underflow unit \#3, 3 zones underflow unit \#4 and 0 zone underflow unit $\# 5$.

\section{Results and Discussions}

Five completion scenarios were created for the reservoir contact portion of the ERD pilot well to meet the objectives of this study. Simulations were run for the multiple completions scenarios, and the results were compared to arrive at the optimum completion design. For each scenario (except for the open-hole), five sensitivity cases were run to determine the optimum scenario. The results below describe the well performance under these optimum cases. It is worth mentioning here that in order to control the fluid influx into the well, a surface rate of $5000 \mathrm{STB} / \mathrm{D}$ was set as a constraint for well start-up in order to avoid high drawdown leading to suction effect of the nearby water into the wellbore, hence avoiding the occurrence of early water breakthrough. Therefore, the target effect of the completion sensitivity installed is seen later in the life of the well rather than initial production rates.

\subsection{Open-hole Barefoot Completion Scenario}

This is considered as the base case for comparison purposes. The coupled simulation is run incorporating an open-hole barefoot completion scenario. The resulting well performance has the profile shown in Figure 5. It can be noticed that the initial production rate is $5456 \mathrm{STB} /$ day; water breakthrough occurs at the $7^{\text {th }}$ year, water cut exceeds $50 \%$ by the $12^{\text {th }}$ year. That is five years after breakthrough, and by the end of the simulation period, the recovery factor attained is $34 \%$. In order to understand the behavior of water influx over time, several cross-sections were examined to determine the water entry points into the lateral and streamlined the movement of water vertically and laterally into different layers of the sector model. The cross-sections displayed in Figures 6 to 8 show water saturation at the beginning of the time (year 0), at water breakthrough time (year 7), and at a later time (year 30), respectively.

From the cross-sections shown in Figures 6 to 8, it is clear that water moves faster in the middle of the lateral horizontally than on either the heel or the toe. This is due to the fact that permeability in the mid-lateral is far greater than the permeability of heel or toe areas. Since the completion is an open hole, there is nothing to hinder the water from taking the easiest path from the injectors to the producer. Therefore, the occurrence of early water breakthrough and bypassing large amounts of oil in the heel and toe sections is inevitable. In order to further confirm the flow profile, a cross-section from completion simulation results is examined in year 10. Most of the water influx is coming from particular zones of the lateral, indicating that the permeability differences are affecting reservoir drainage efficiency. However, the heel and toe sections are still producing pure oil without any water cut.

Although open-hole completion is favorable in cases of competent rocks and stable consolidated formations that will not collapse, such as carbonate rocks, when the well is open to 
production, water and gas coning tendency is high, and also they are difficult to stimulate using either bull heading from surface or running coiled tubing to TD. This is because the acid preferentially moves towards the higher permeability areas. This leads to high permeability regions being overstimulated and allowing higher water movement to the wellbore while other areas remaining under-stimulated and poorly productive. More importantly, this open hole barefoot completion design does not allow any contingency for shutting off unanticipated water production either through fractures or high permeability streaks. Pressure drop introduced by conventional completion is usually negligible compared to the drawdown.
Besides, the heel-toe effect is largely noticed in the open-hole completion scenario, especially when the reservoir in question is without huge permeability variations. Hence, in order to complete the ERD wells, the desired completion design will have to satisfy some minimum well intervention requirements in addition to controlling fluid flow profiles. These include compartmentalization of the reservoir intervals to allow for an effective acid or profile control job. The compartmentalization is also desired to help verify the inflow and outflow contributions along the production hole, allowing opportunities for production logging and other reservoir surveillance and management in the future.

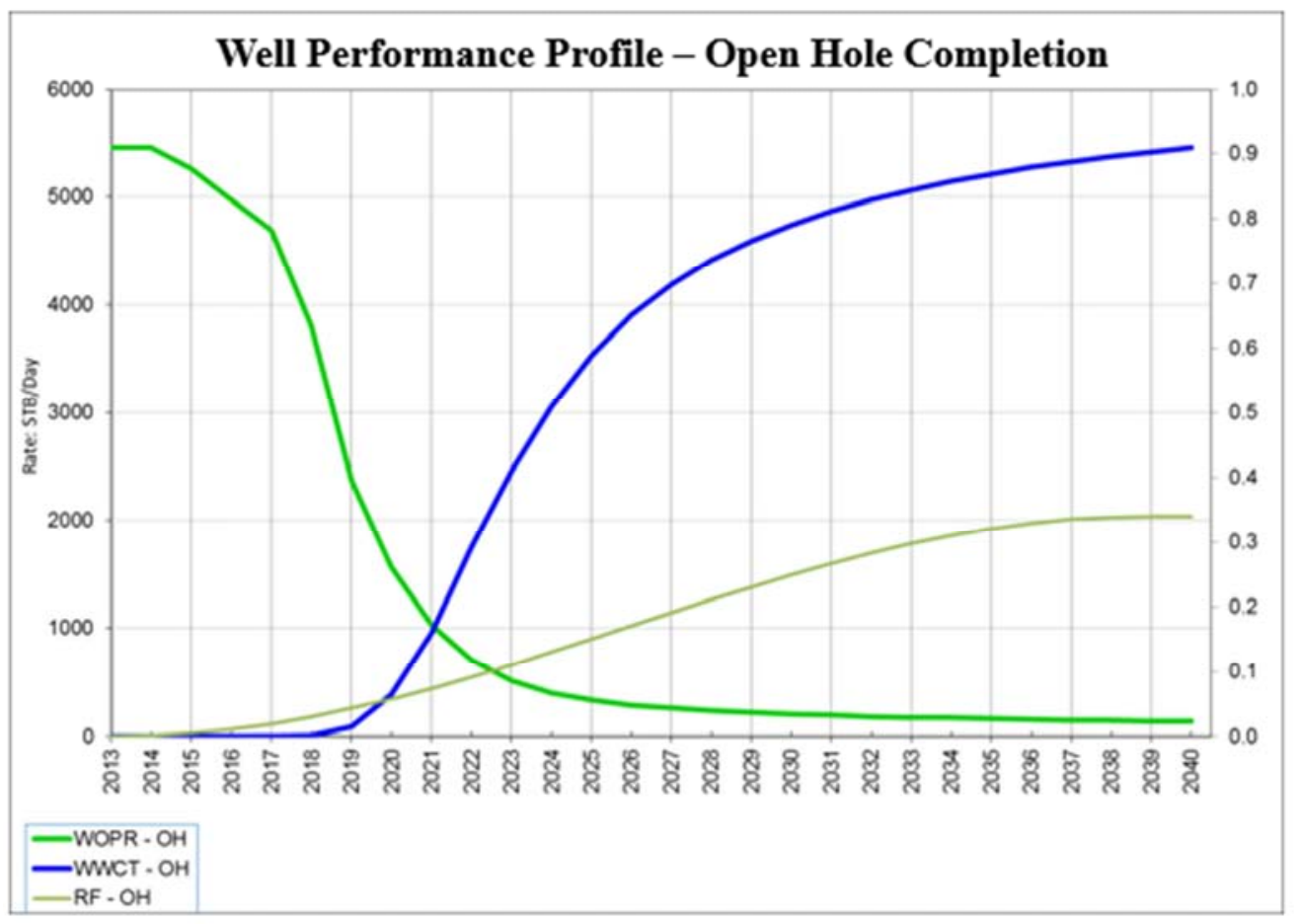

Figure 5. Predicted performance of open-hole completion.

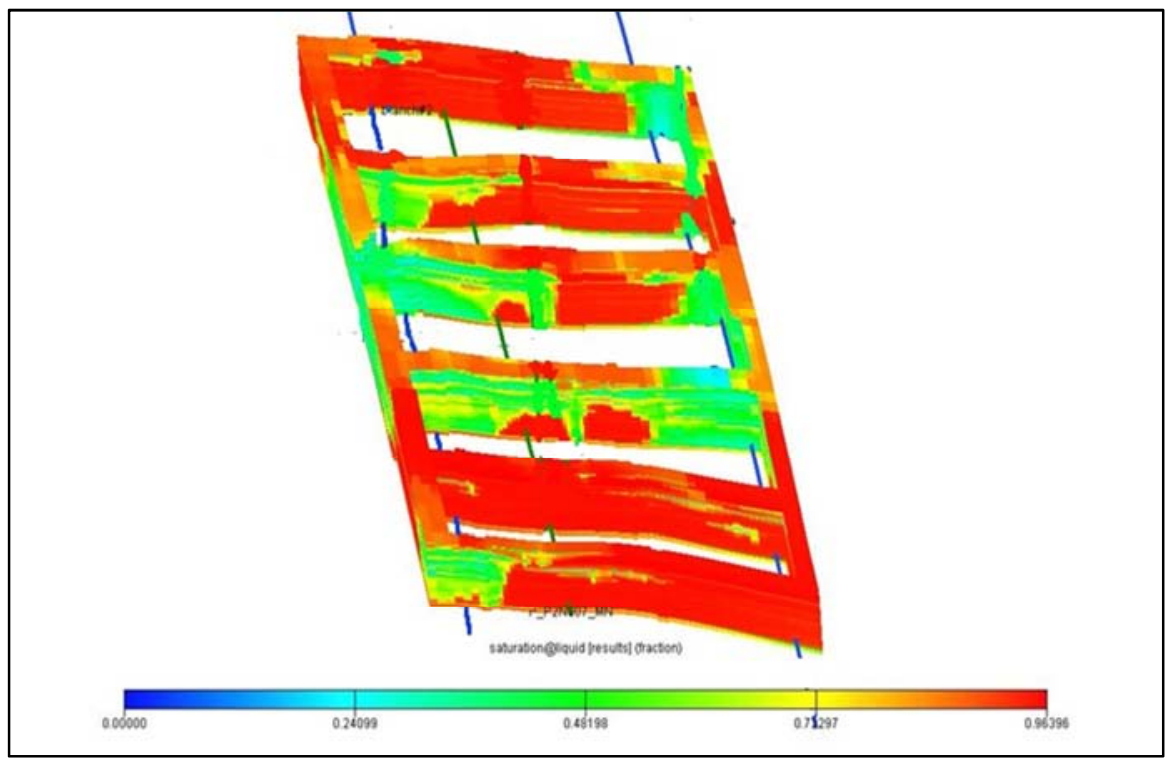

Figure 6. Oil Saturation at early time (year 0) - Open Hole Completion Case. 


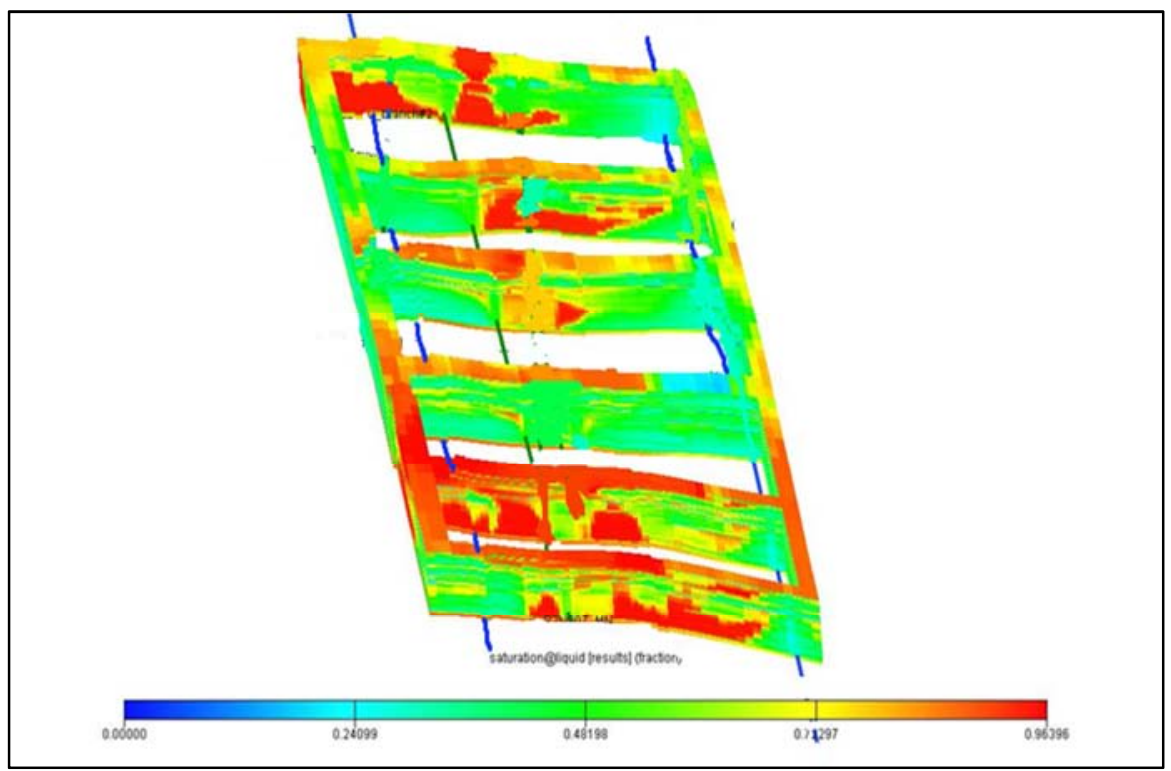

Figure 7. Oil Saturation after water breakthrough time (year 7) - Open Hole Completion Case.

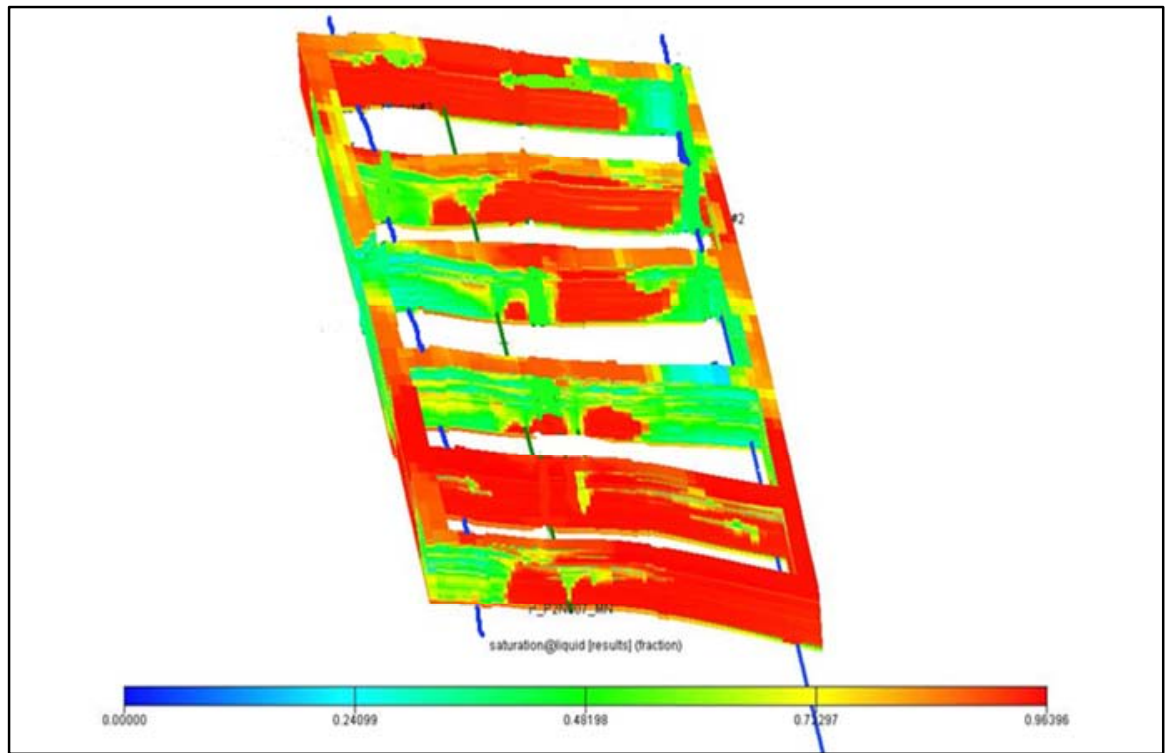

Figure 8. Oil Saturation at late time (year 30) - Open Hole Completion Case.

\subsection{Pre-perforated Liner Completion}

The pre-perforated liner is a liner that has uniform slot density and diameter along the liner all the way from the heel to the toe. Figure 9 shows the typical pre-perforated liner completion. The pre-perforated liner is carefully designed by selecting the size and pattern of the perforated holes to satisfy both flow uniformity and acidization requirements. A total number of 5 sensitivity runs are performed. It was desirable to maximize the diameter and the number of holes from the point of view of stimulation and inflow with due considerations of tension and bending loads, as large holes would reduce the mechanical capacity of the completion string.

The steady-state simulator uses finite element analysis on various hole patterns and sizes that maximized the hole density while still providing enough structural integrity to run the completion string. This resulted in a hole pattern with 20 holes per foot at 90-degree phasing, compartmentalized in 16 segments along the well. The resulting well performance profile is shown in Figure 10. The figure indicates that the initial production rate is $5456 \mathrm{STB} /$ day, water breakthrough occurs at year 7 (same as open-hole scenario), water cut exceeds $50 \%$ by year 13 , and by the end of the simulation, the recovery factor attained is $37 \%$. Although the recovery factor of this completion scenario is only $3 \%$ more than the open hole case, which seems a small figure at the first look, it must be noticed that significant economic value can be achieved from the reduced water influx and associated cost of lifting, separation and fluid handling at surface. 


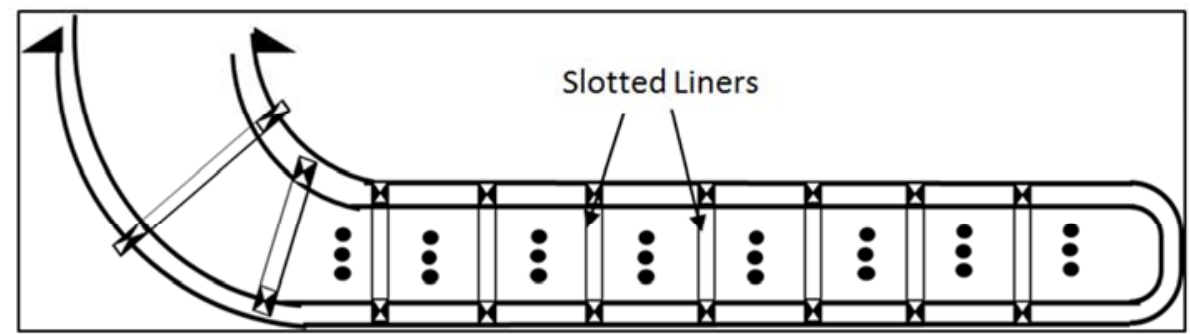

Figure 9. Pre-perforated liner completion sketch.

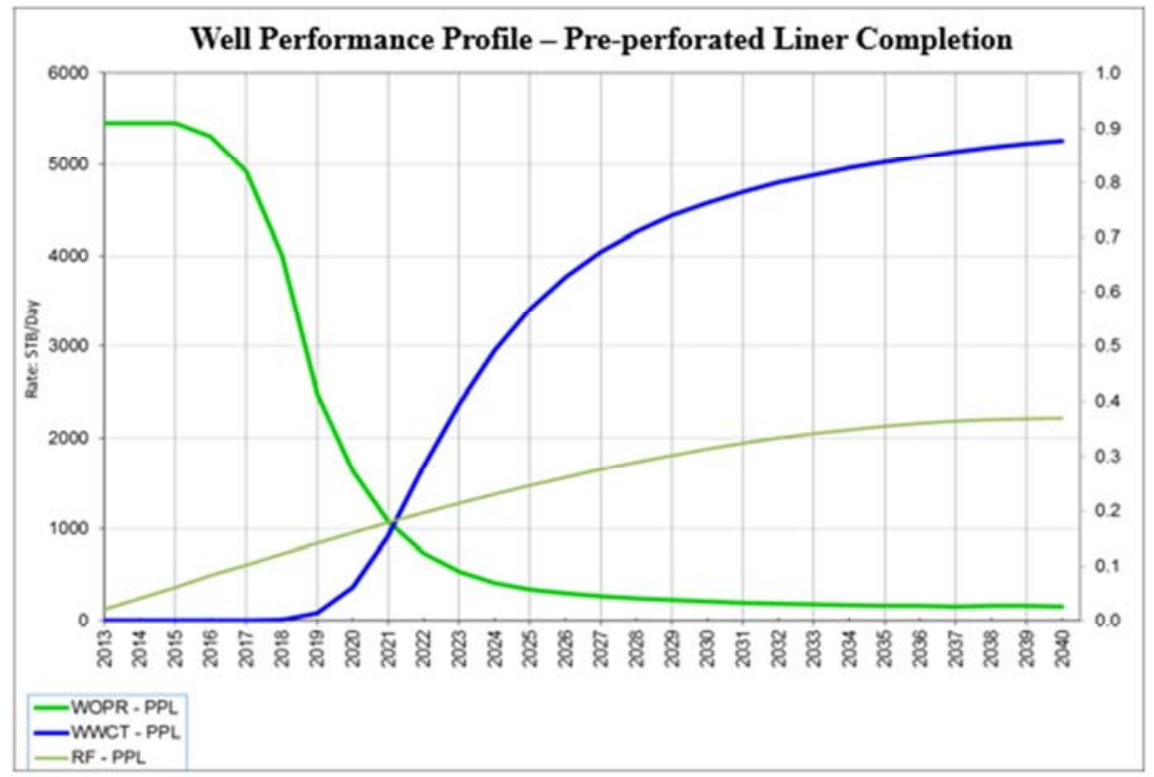

Figure 10. Predicted performance of Pre-perforated liner completion.

\subsection{Limited Entry Liner Completion}

The limited entry liner (LEL) is similar to a pre-perforated liner except for the fact that hole density and hole size were varied in each compartment according to the permeability (and other factors that resists flow) of that compartment in order to achieve uniform influx and bullhead acidization requirements. A typical LEL completion is sketched in Figure 11. LEL completions use perforation friction pressure to control fluid influx from each lateral compartment into the wellbore. The permeability of that section determines the size and pattern of holes in each compartment in order to achieve uniform influx across the lateral. Therefore, LELs are considered as an optimization over the pre-perforated liners in the way that they control pressure drop across each compartment according to its properties. Many iterations are done in order to optimize both the hole sizes and shot density for each compartment. Over 40 sensitivity simulation runs are conducted to achieve the best possible recovery factor. This careful consideration of the pressure drop across the compartments resulted in the LEL design presented in Table 5, and the coupled simulation is run incorporating the optimized data. The resulting well performance has the production profile (Figure 12), which shows an initial production rate of 5456 STB/day; water breakthrough occurs at year 7; water cut exceeds $50 \%$ by year 14 and recovery of $45 \%$ by the end of simulation.

Table 5. LEL design across all 16 compartments.

\begin{tabular}{|c|c|}
\hline Compartment \# & LEL design \\
\hline 1 & 4 SPF (1/4") \\
\hline 2 & $2 \operatorname{SPF}(1 / 4 ”)$ \\
\hline 3 & $1 \mathrm{SPF}(1 / 4 ”)$ \\
\hline 4 & $1 \mathrm{SPF}(1 / 4 ")$ \\
\hline 5 & $2 \mathrm{SPF}(1 / 4 ")$ \\
\hline 6 & $1 \mathrm{SPF}(1 / 4 ")$ \\
\hline 7 & $2 \operatorname{SPF}(1 / 4 ")$ \\
\hline 8 & $1 \mathrm{SPF}(1 / 4 ")$ \\
\hline 9 & $2 \mathrm{SPF}(1 / 4 ")$ \\
\hline 10 & $1 \mathrm{SPF}$ (1/4”) \\
\hline 11 & $1 \mathrm{SPF}(1 / 4 ”)$ \\
\hline 12 & $1 \mathrm{SPF}$ (1/4") \\
\hline 13 & 4 SPF (1/4”) \\
\hline 14 & $2 \operatorname{SPF}(1 / 4 ")$ \\
\hline 15 & 4 SPF (1/4") \\
\hline 16 & 4 SPF (1/4”) \\
\hline
\end{tabular}

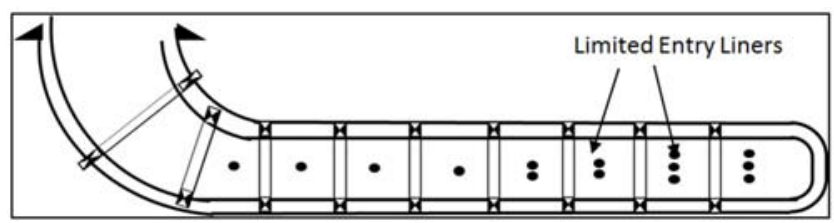

Figure 11. Limited Entry Liner completion sketch. 


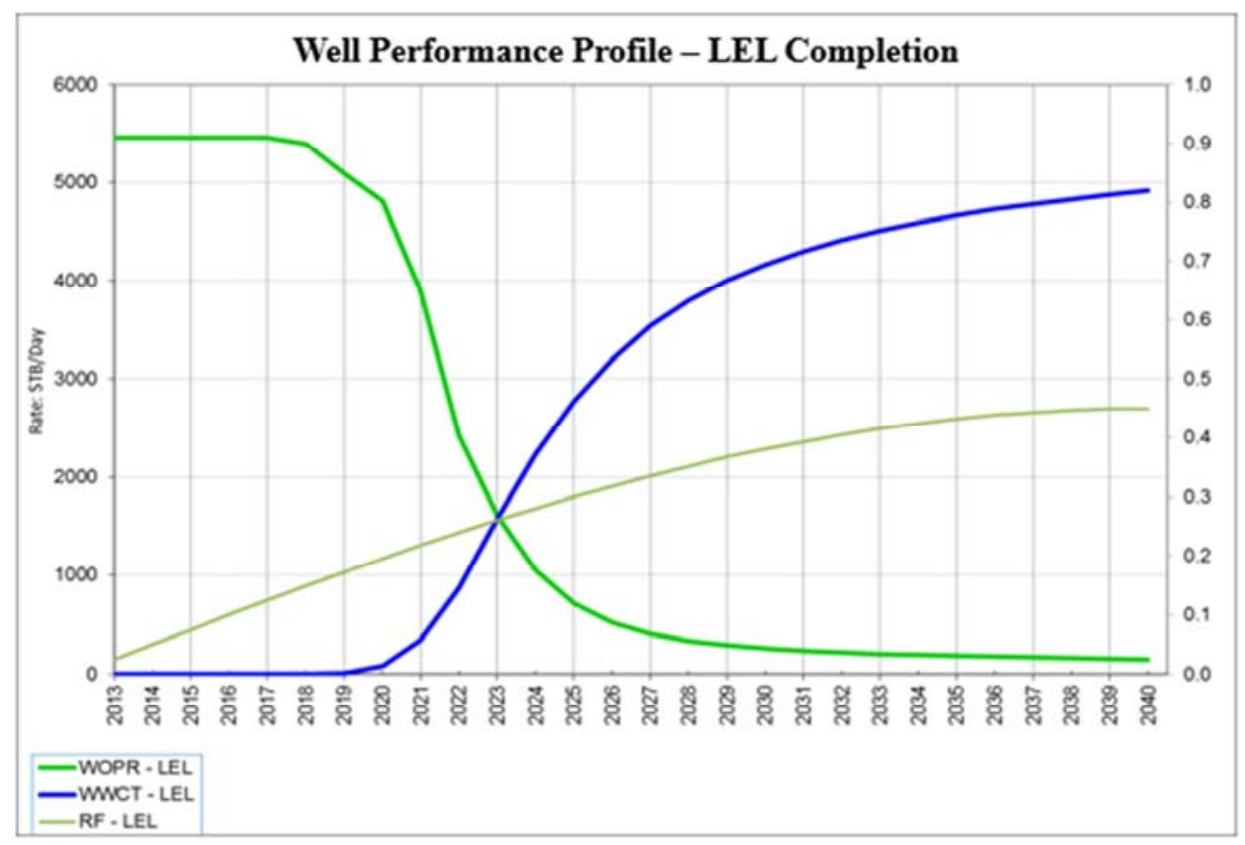

Figure 12. Predicted performance of Limited Entry Liner completion.

\subsection{ICD-Integral Completion}

While analyzing with the steady-state simulator, several ICD configurations and scenarios are investigated, and the optimal completion solutions are reported here. During the process of simulation, we determined the optimal number and location of the ICDs, nozzle size, the number, and zonal isolation along the particular reservoir. It took a total number of 12 iterations to optimize the ICD design. The target of this analysis was to examine produced fluid in an ICD completion, compared to well productivity from other completion scenarios. It must be kept in mind that, if the permeability had been constant along the reservoir, ICDs would not make any particular difference. Therefore, the permeability profile along the lateral is examined to arrive at the optimum ICD configuration. A typical ICD-integrated completion is displayed in Figure 13.

Careful consideration of the pressure drop across the compartments resulted in the ICD design presented in Table 6. The coupled simulation is run incorporating an ICD-Integral completion. The resulting well performance has the profile shown in Figure 14. It can be noticed from Figure 14 that the initial production rate is $5456 \mathrm{STB} /$ day, water breakthrough occurs at year 8 , water cut exceeds $50 \%$ by year 14 , and by the end of the simulation, recovery factor attained is $59 \%$. In order to check the results of this optimized completion technique, a cross-section from completion simulation results is examined at year 10, as it has been done for other cases. This scenario shows a significant reduction in the water influx volume, compared to all other completion scenarios discussed so far. The reason behind such flow uniformity is due to the difference of appropriate pressure drop created by the ICDs in each compartment. The pressure drop created across each nozzle in the ICD is large enough to regulate production from higher permeable zones and promote production from zones with low permeability. Also, it regulated water production from higher permeability mid-section of the well, which improved production from the toe section.

Table 6. ICD design across all 16 compartments.

\begin{tabular}{ll}
\hline Compartment \# & ICD design (N stands for Nozzles) \\
\hline 1 & $4 \mathrm{~N}, 4 \mathrm{~mm}$ \\
2 & $4 \mathrm{~N}, 2 \mathrm{~mm}$ \\
3 & $1 \mathrm{~N}, 2 \mathrm{~mm}$ \\
4 & $2 \mathrm{~N}, 2 \mathrm{~mm}$ \\
5 & $4 \mathrm{~N}, 2 \mathrm{~mm}$ \\
6 & $1 \mathrm{~N}, 2 \mathrm{~mm}$ \\
7 & $2 \mathrm{~N}, 4 \mathrm{~mm}$ \\
8 & $1 \mathrm{~N}, 2 \mathrm{~mm}$ \\
9 & $2 \mathrm{~N}, 4 \mathrm{~mm}$ \\
10 & $1 \mathrm{~N}, 2 \mathrm{~mm}$ \\
11 & $1 \mathrm{~N}, 2 \mathrm{~mm}$ \\
12 & $1 \mathrm{~N}, 4 \mathrm{~mm}$ \\
13 & $4 \mathrm{~N}, 4 \mathrm{~mm}$ \\
14 & $2 \mathrm{~N}, 4 \mathrm{~mm}$ \\
15 & $4 \mathrm{~N}, 4 \mathrm{~mm}$ \\
16 & $4 \mathrm{~N}, 4 \mathrm{~mm}$ \\
\hline
\end{tabular}

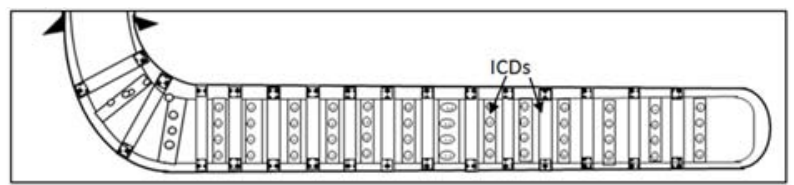

Figure 13. ICD-integrated completion sketch. 


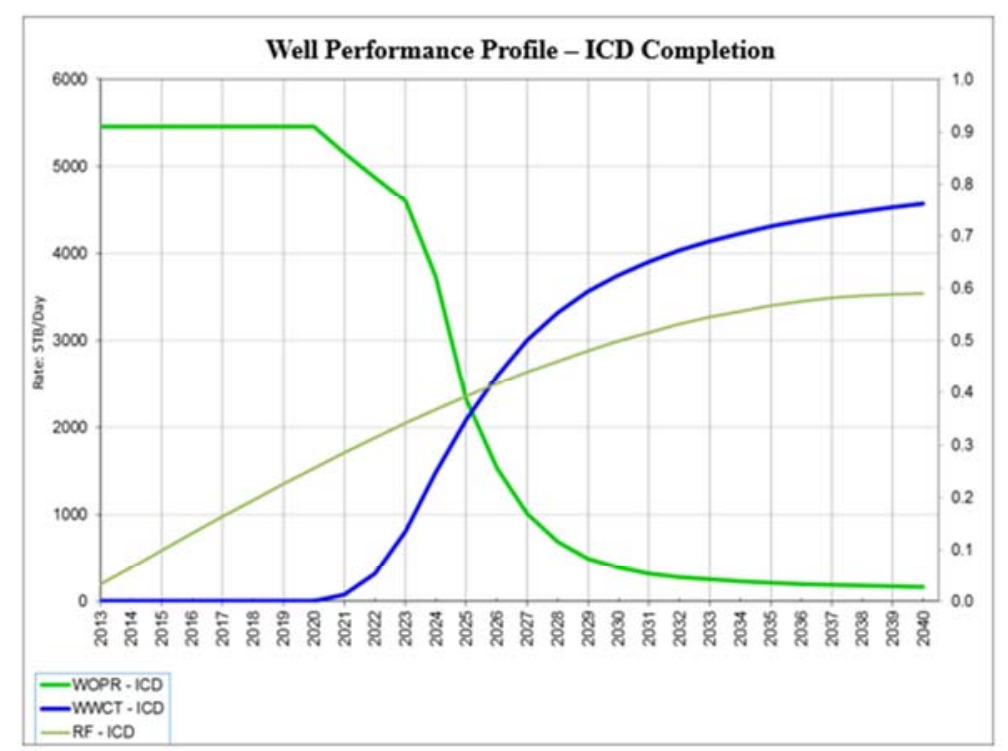

Figure 14. Predicted performance of ICD completion.

\subsection{ICD-LEL Combination Completion}

In view of the previous analysis, it was apparent that the ICD-integrated design is superior to the LEL. ICD completion may not be able to justify the cost if the segment of the reservoir is relatively homogeneous. In such cases, the LEL completion would be more economical. This issue triggered the idea of evaluating a hybrid design that combines both the ICD-integrated and LEL in order to optimize both the recovery and the completion cost. A model completion string of this type is displayed in Figure 15. The coupled simulation is run incorporating a combination of ICDs and LEL. The resulting well performance has the profile shown in Figure 16. It can be noticed from this figure that the initial production rate is $5456 \mathrm{STB} /$ day, water breakthrough occurs at year 8 , water cut exceeds $50 \%$ by year 14 , and by the end of the simulation, recovery factor attained is $62 \%$. In order to check the results of this completion optimization technique, a cross-section from completion simulation results is examined in year 10. This scenario presents the greatest reduction in the water influx volume compared to all other completion scenarios. This scenario also leads to an increase in production rate from the toe of the lateral where there is no pressure reduction applied by ICDs. However, not only oil production increases, but also water production is reduced. Nonetheless, the overall recovery factor for this scenario is $3 \%$ more than that of the ICD-Integral scenario as well as the cost of this completion string is expected to be less than that of ICD-Integral completion string.

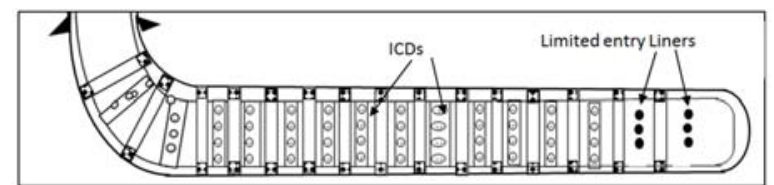

Figure 15. ICD-LEL completion sketch.

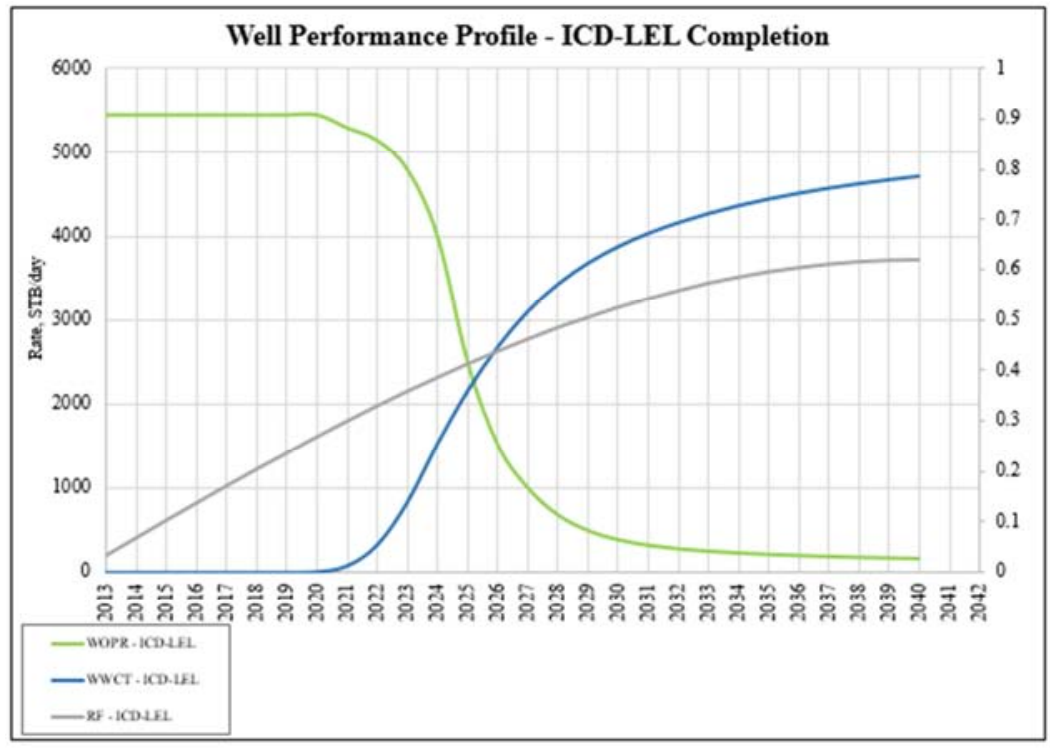

Figure 16. Predicted performance of ICD-LEL combination completion. 


\section{Discussion}

Comparison of Different Scenarios: In order to determine the optimum scenario, three production parameters were compared, which are oil production rate, water cut, and recovery factor. The oil production rate versus time is plotted for all five scenarios, as shown in Figure 17. It can be noticed that the production rate plots for all scenarios follow the same trend with time. However, the rate increases with the sophistication of completion tools. It can be deduced from this figure that the combination case scenario provides the highest oil production rate.

The water cut versus time is plotted for all five scenarios, as shown in Figure 18. It can be seen that the water cut for all scenarios follows a similar trend with time. However, water breakthrough starts later as more sophisticated completion tools are used. It is worthy of mentioning that the least amount of water is produced with ICD-integral completion; the combination completion scenario produces more water from the toe section of the well where pre-perforated liner is installed. The recovery factor versus time is plotted for all five scenarios and presented in Figure 19. It is evident that the recovery factor for all scenarios follows the same trend with time with the combination completion scenario having the highest recovery.

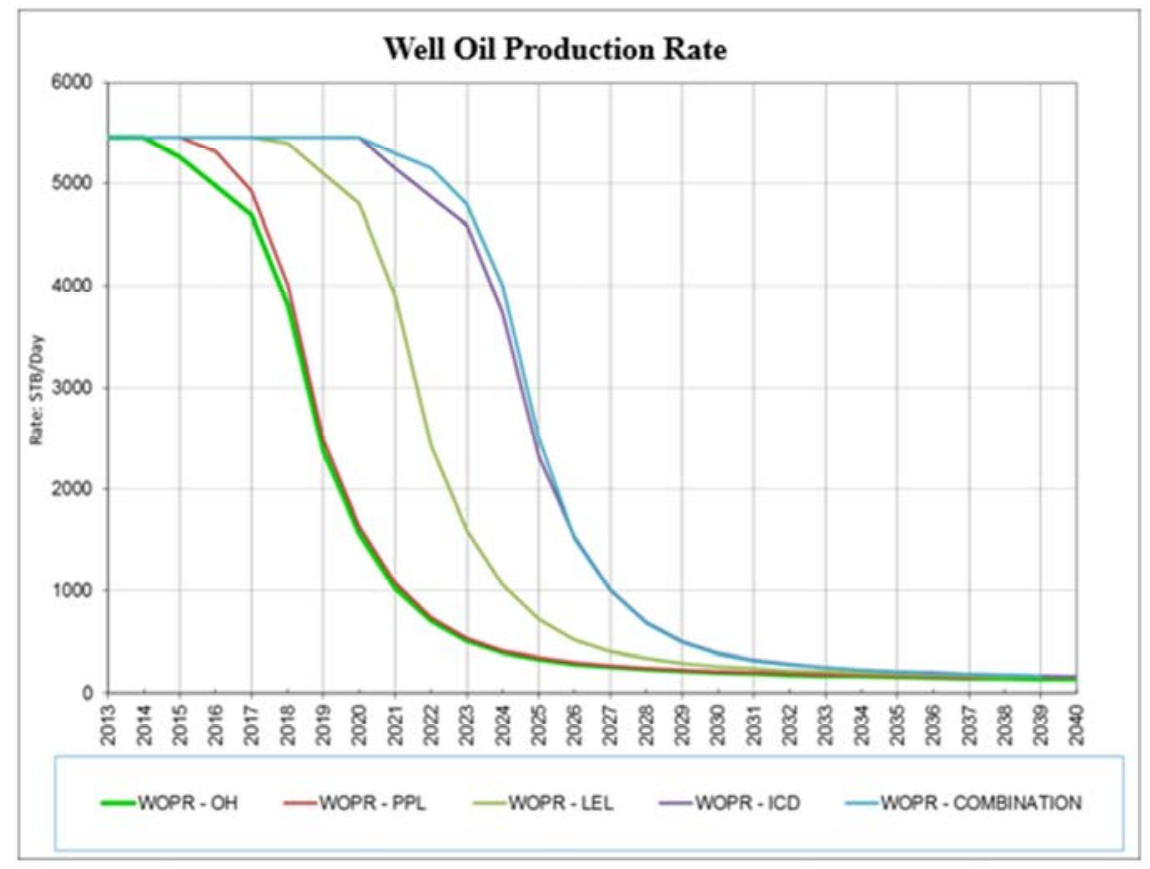

Figure 17. Oil production rate comparison for all five scenarios.

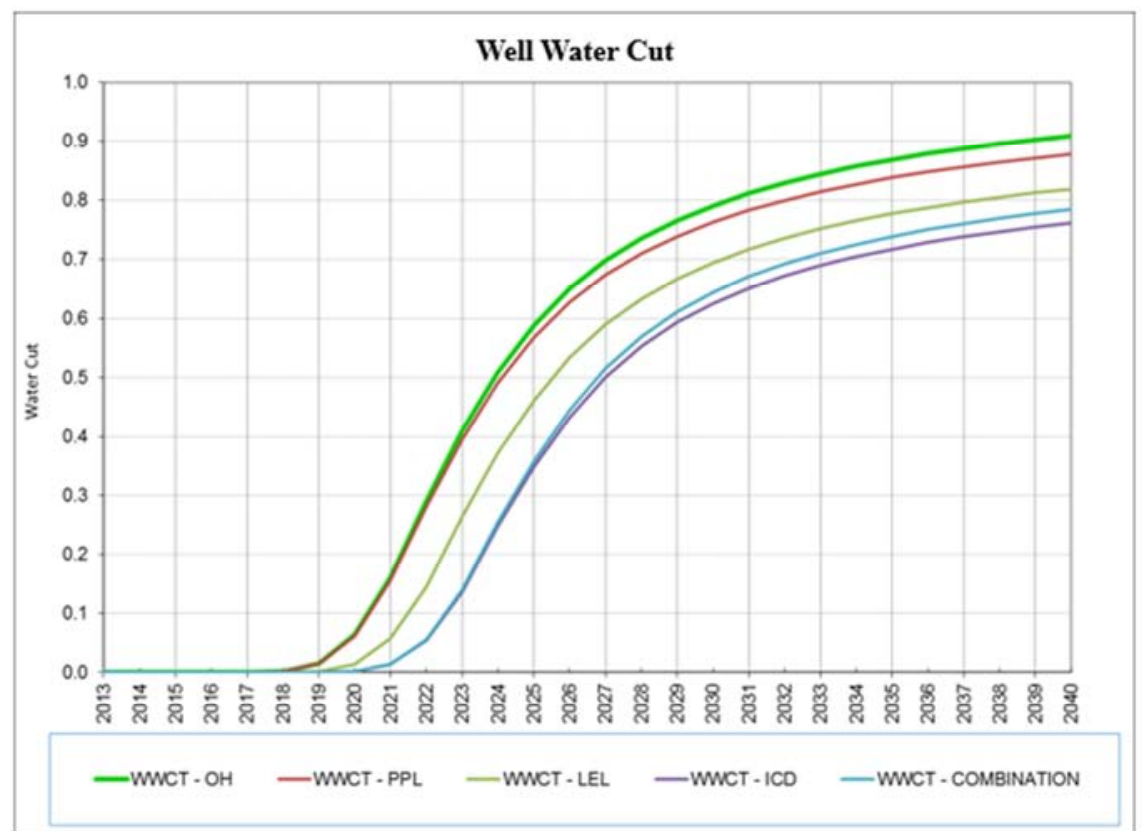

Figure 18. Water cut comparison for all five scenarios. 


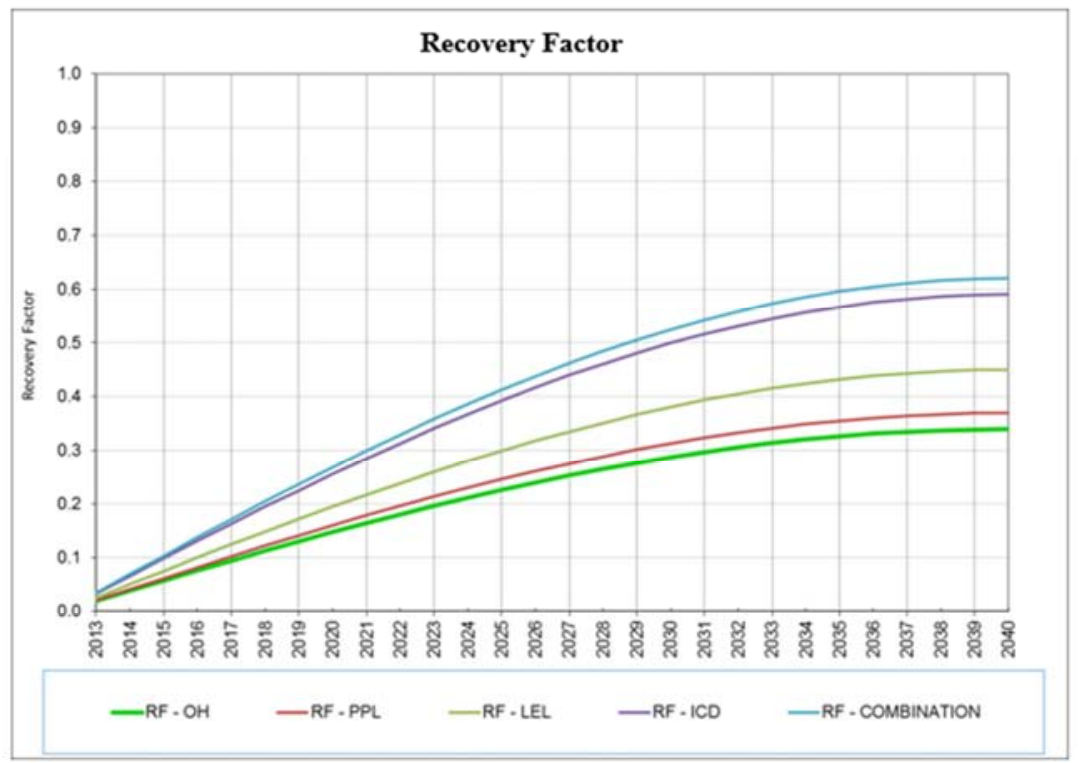

Figure 19. Recovery factor comparison for all five scenarios.

\section{Conclusions}

Five completion scenarios were considered for a long horizontal well with severe permeability heterogeneity for a Middle-East oil reservoir; Open hole barefoot completion, pre-perforated liner completion, engineering limited entry liner completion, ICD-Integrated completion, and a newly proposed completion type named ICD-LEL hybrid completion.

Detailed simulation runs were performed with a new procedure by which both flows inside the reservoir and across the completion were modeled. This objective was accomplished by coupling two simulators, the steady-state simulator, and the dynamic simulator. By implementing this procedure, the detailed flow is captured from each completion scenario, and the required pressure drop in the lower completion string was adjusted in order to achieve flow uniformity across the length of the lateral. From the analysis of the coupled simulation output, the following conclusions were drawn:

1. The performance of the pre-perforated liner is relatively close to the open-hole case.

2. The Limited entry liner scenario had a higher recovery factor than the open-hole and the PPL.

3. The ICD integrated completion scenario had even higher recovery than the LEL completion.

4. The ICD-LEL combination scenario achieved the highest recovery and lowest overall water cut amongst the five completion scenarios.

5. The ICD-LEL combination presented in this work provides an optimum design for this specific case.

\section{Appendix}

\section{Appendix 1. Modifying and Coupling Reservoir Model}

The primary advantage of using a steady-state simulator to model a well completion is that the well is represented in more detail. The linkage can also handle many-to-one mapping from the steady-state simulator segments to the dynamic simulator grid. However, the base model may not be fit-for-purpose for the coupling study and thus needs modifications.

The well completion model may affect the required resolution of the dynamic simulation grid. This is generally not an issue with simple completions that do not vary much along the completion length. Even though the linkage supports many-to-one coupling, the pressures of the steady-state simulator nodes are averaged when sent back to the corresponding dynamic reservoir connection. If the completion string contains a small feature that acts as a barrier to flow, such as a swell packer, its effect on well performance on the dynamic simulator side may be lost. Even if the location of the packer is manually represented as an R-scale multiplier, its effect will not be properly captured. Figure 20 represents a non-ideal layering of the model [15].

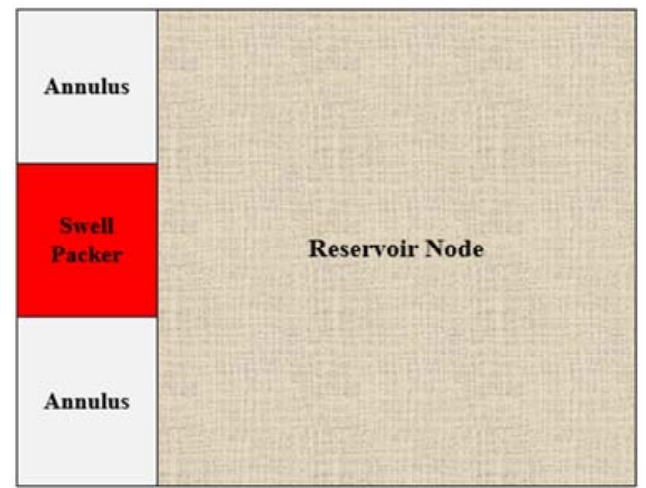

Figure 20. Dynamic model layer resolution respective of completion design.

The layer thickness of the simulation model in the near-wellbore region should be roughly the length of the smallest feature in the completion, which with the present 
simulator can be down to $1 \mathrm{ft}$. The simulation model layers should not be any finer than those in the geologic model. It is noteworthy to mention that if the layer thickness of the reservoir model need refinement, it could be done by either refining the layers in the entire model or by creating a local grid refinement (LGR). Additionally, it is possible to have multiple LGR regions in the parent grid. An LGR grid can be nested within another LGR, but two or more LGR regions cannot be overlapped. Having multiple LGR regions may be useful in case multiple wells need to be coupled to the dynamic model [18].

The simulation model must be quality checked for any changes to the grid. Overall reservoir performance and individual well performance ought to be similar to those in the original model. If results are different from those in the original model, it is important to understand the reasons for those differences. For instance, refining the grid around a well may result in earlier breakthrough because the pressure field around the well is better represented in the new model. It is often useful to perform a grid refinement study to evaluate performance versus accuracy. The goal is to ensure that the accuracy of the coupled model is adequate for the purposes of the study.

Converting the Well to a Multi-node Well Configuration. In a two-node well, a virtual well connection (VWC) connects the virtual well node (VWN) with the well node [17]. All of the reservoir nodes penetrated by the well track are linked to the VWN through virtual reservoir connections (VRC). Flow along the VRC is a function of potential drop between the reservoir and the well and corrected for depth with a gravity term. The computational boundary is set at the well node, and its depth is set to the wellhead depth. The VWN depth is set at the average perforation depth. A flow model is assigned to the VWC to account for the pressure drop along the completion from the reservoir to the wellhead.

In a coupled model, the number of VWN must equal the number of reservoir nodes connected to the well (VRC) plus 1. The extra well node corresponds to the cemented blank piping that is placed at the top of the completion in the steady-state simulator. Figure 21 is a schematic of the dynamic model multi-node well used to couple with the steady-state simulator.

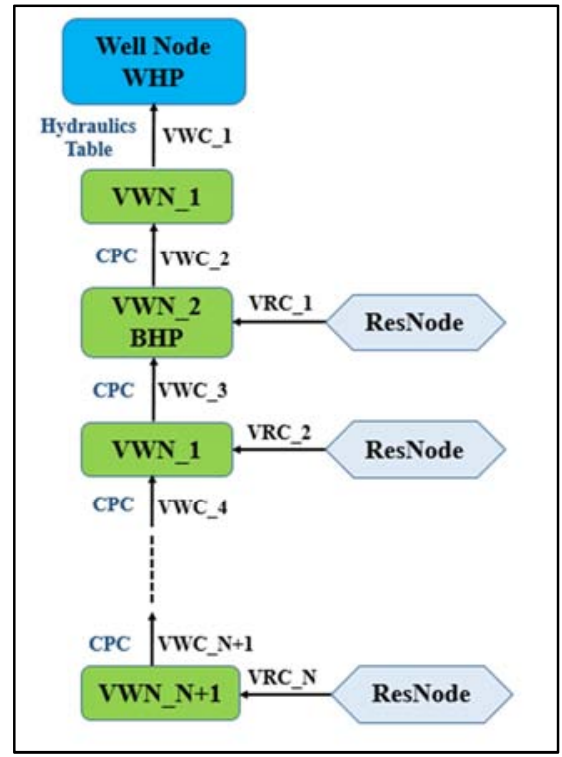

Figure 21. Schematic of the dynamic model multimode well used to couple with the steady-state model.

\section{Appendix 2. Completion Design}

The following types of completion tools are used in analyzing the fluid flow issues:

1. Open Hole: simple open hole.

2. Slotted Liner: un-cemented slotted liner with rectangular slots.

3. Limited Entry Liner: slotted liner with variable slot density.

4. Generic ICD: a general application for nozzle based ICDs. The pressure drop formulation is based on Bernoulli's principle. For a single nozzle, the pressure drop is calculated as follows [17].

$$
\mathrm{P}=0.5 \cdot \rho \cdot \mathrm{v}_{2} / \text { flow coefficient }{ }_{2}=0.5 \cdot \rho \cdot \mathrm{q}_{2} / \mathrm{A}_{2} / \text { flow coefficient }{ }_{2}
$$

Where $P$ is the pressure drop across the nozzle, $\rho$ is the average fluid density, $\mathrm{v}$ is the fluid velocity through the nozzle, $\mathrm{q}$ is the fluid flow rate through the nozzle, and A is area of the nozzle.

Simulation Region. The steady-state model does not need to include the entire well, but it should encompass all producing regions of the well. The Reservoir Connections, define what inflow the well will see in the steady-state model. If the model passes through a keyed out region or a Reservoir Connection with $\mathrm{R}$ Value $=0$, the steady-state simulator will enforce that there is no Reservoir/Well communication (Jackson et al., 2012).

\section{Appendix 3. Segmenting}

The strategy employed in this study is to match each steady-state simulator segment to one or more dynamic simulator reservoir nodes. The simplest way to prepare a model for coupled simulation is to use just enough segments to describe the variation in completions. Flow into partially penetrated reservoir connections is calculated with a scaled $\mathrm{R}$-Value on the steady-state simulator. The dynamic simulator continues to use the uncorrected R-Value and thus calculates a different flow rate. Likewise, it calculates flow for connections that are completely disconnected on the steady-state simulator side because of the completion type or in case they are disconnected manually [18].

When there are multiple reservoir nodes matched to one segment, the steady-state simulator will add internal nodes. For example, if there is a $10 \mathrm{ft}$ segment connected to two $5 \mathrm{ft}$ thick reservoir cells, the steady-state simulator will add an internal node to separate the connections. It will return the 
average pressure and the total flux of the two new segments for the reservoir node. However, it cannot consistently handle node spacing of less than $1 \mathrm{ft}$. In the dynamic simulator, due to the trajectory of the well with respect to the cells being intersected, there can be partial pinch-outs leading to reservoir connections to cells with $1 \mathrm{ft}$. or less. Figure 22 describes the above and displays a schematic of the linkage between both simulators (Wan et al., 2008).

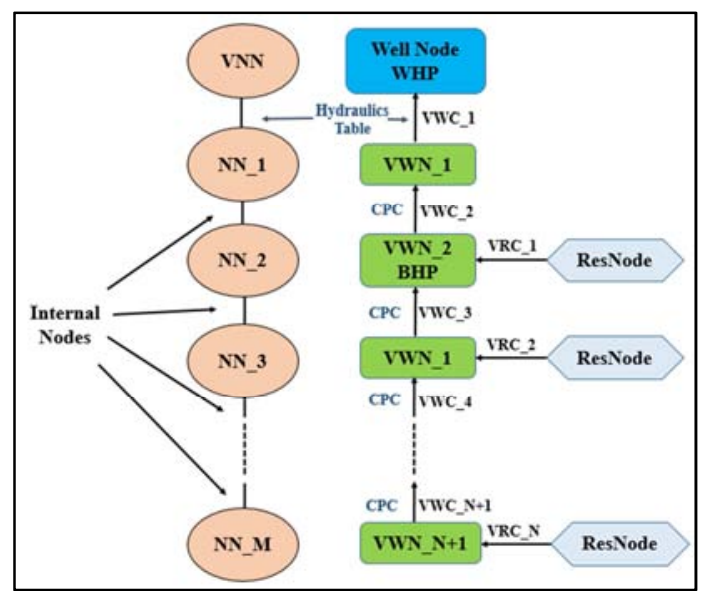

Figure 22. Example of linkage between the steady-state and dynamic simulators.

\section{Appendix 4. Limitations of the Coupled Modeling}

After explaining the advantages of using the coupled simulation technique, below is a list of the limitations of the coupled model [18]:

1. Crossflow

a) The current linkage setup does not handle crossflow effects between the well and the reservoir. Wells (and their virtual well nodes) are identified as either producers or injectors in the dynamic simulator. If the well is a producer, the flow along at least one of its reservoir connections must be producing. This is because the mole fraction entering the well node is estimated by dividing the composition of the incoming fluid by the producing flow rate. If the producing flow rate is 0 because the flow is now injecting, a divide by 0 condition will be present and vice versa for an injecting well.

b) In a linked well, there is only one reservoir connection to each virtual well node. Therefore, if the well is a producer, the flow along that one connection cannot switch from producing to injecting without violating the divide by 0 constraint. Instead, the virtual reservoir connection is disconnected.

c) This situation will occur even in a standalone multi-node well that has one-to-one matching between well nodes and reservoir nodes.

d) Currently, there is no tested work around to calculate crossflow.

2. Pressure from isolated annulus regions

The steady-state simulator does not calculate pressure in annulus regions, which are not connected to the tubing.

\section{Nomenclature}

\author{
$\mathrm{A}=$ area of nozzle. \\ $\mathrm{CPC}=$ controlled pressure change \\ DTS $=$ Distributed Temperature Sensor \\ $\mathrm{ERD}=$ Extended Reach Drilling. \\ GOR $=$ Gas Oil Ratio. \\ ICD $=$ Inflow Control Device. \\ LEL $=$ Limited Entry Liner. \\ LGR $=$ Local Grid Refinement. \\ $\mathrm{MRC}=$ Maximum Reservoir Contact. \\ $\mathrm{P}=$ Pressure drop across nozzle. \\ PPL $=$ Pre-perforated Liner. \\ $\mathrm{q}=$ fluid flow rate through nozzle. \\ $\rho=$ average fluid density. \\ $\mathrm{V}=$ fluid velocity through nozzle. \\ VRC $=$ Virtual Reservoir Connection. \\ $\mathrm{VWC}=$ Virtual Well Connection. \\ $\mathrm{WOR}=$ Water Oil Ratio.
}

\section{Acknowledgements}

The authors acknowledge the Khalifa University of Science and Technology for the support and encouragement provided in undertaking this study.

\section{References}

[1] Allen, F., Tooms, P., Conran, G. and Lesso, B. "Extended reach drilling: Breaking the 10-km barrier." Oilfield Review. Winter 1997. Pp 32-47.

[2] Satter, A. and Iqbal, G. M. (2016). "Reservoir Engineering: The Fundamentals, Simulation, and Management of Conventional and Unconventional Recoveries". ISBN-978-0-12-800219-3.

[3] Verma, C. et al. (2017). Drilling Optimization of Extended Reach Multilateral Wells to Maximize Reservoir Contact in Carbonate. SPE-186982. Presented at the Asia Pacific Oil \& Gas Conference and Exhibition, Jakarta, Indonesia Oct 2017.

[4] Yang, M. Li, H., Wang, Y. and Jiang, R. (2019). "Numerical Modelling for the Optimum Design of Horizontal Well. Completions with PSCs in Water Drive Reservoirs." Arabian Journal for Science and Engineering. Vol- 44. Pp. 5215-32.

[5] Chammout O. J., Ghosh, B and Alkhi M. Y. (2017). "Downhole flow controllers in mitigating challenges of long reach horizontal wells: A practical outlook with case studies". Journal of Petroleum and Gas Engineering. Vol. 8 (9), pp. 90-103.

[6] Jha, P., Smith, C. and Metcalfe R. W. (2016). "Insight Into the Heel-Toe Effect of a Long Horizontal Wellbore Based on a Hybrid Numerical Method". Journal of Energy Resources Technology. Vol. 138 (1): Pp 12905-13.

[7] Minulina, P., Al-Sharif, S., Zeito, G. A. and Bouchard, M. J. (2012). "The Design, Implementation and Use of Inflow Control Devices for Improving the Production Performance of Horizontal Wells". SPE-157453. Presented at SPE International Production and Operations Conference and Exhibition, Doha, Qatar. May 2012. 
[8] Daneshy, A., Guo, B., Krasnov, V. and Ziminet, S. (2010). "ICD Design: Revisiting Objectives and Techniques. SPE-133234. Presented at the SPE Asia Pacific Oil and Gas Conference and Exhibition, Brisbane, Australia, Oct 2010.

[9] Garcia, L., Coronado, M. P., Russell, R. D., Garcia, G. A. and Peterson, E. R. (2009). "The First Passive Inflow Control Device That Maximizes Productivity during Every Phase of a Well's Life". IPTC-13863. Presented at International Petroleum Technology Conference, Doha, Qatar, Dec 2009.

[10] . Ouyang, L. (2009). "Practical Consideration of an Inflow-Control Device Application for Reducing Water Production". SPE-124154. "Presented at SPE Annual Technical Conference and Exhibition, New Orleans, Louisiana, USA. Oct 2009.

[11] Aadnoy, B. and Hareland, G. (2009). "Analysis of Inflow Control Devices". SPE-122824. Presented at Offshore Europe, Aberdeen, United Kingdom, Sept 2009.

[12] Gao, C., Rajeswaran, R. T. and Nakagawa, E. Y. (2007). "A literature review on smart well Technology". SPE-106011. Presented at SPE Production and Operations Symposium, Oklahoma, USA, March- April 2007.

[13] Burtsev, A., Ascanio, F. A., Mollinger, A. M., Kuvshinov, B. and De Rouffignac, E. P. (2006). "Limited Entry Perforations in HVO Recovery: Injection and Production in Horizontal Wells". SPE-102656. Presented at SPE Russian Oil and Gas Technical Conference and Exhibition, Moscow, Russia, 3-6 Oct 2006.
[14] Chow, H., Blount, C. G. and Hilleary, N. (2009). "Annular Isolation of Horizontal Slotted Liners with Chemical External-Casing Packers". SPE-121643. Presented at SPE/ICoTA Coiled Tubing \& Well Intervention Conference and Exhibition, Woodlands, Texas, March- April 2009.

[15] Wang, J., Dale, B. A., Ellison, T. K., Benish, T. G. and Grubert, M. (2008). "Coupled Well and Reservoir Simulation Models to Optimize Completion Design and Operations for Subsurface Control". SPE-113635. Presented at Europec/EAGE Conference and Exhibition, Rome, Italy. June 2008.

[16] Thornton, K., Soliman, M. Y. and Jorquera, R. A. (2010). "Optimization of Inflow Control Device Placement and Mechanical Conformance Decisions Using a New Coupled Well-Intervention Simulator". SPE-139435. Presented at SPE Latin American and Caribbean Petroleum Engineering Conference, Lima, Peru. Dec 2010.

[17] Carvajal, G. A., Saldierna, N., Querales, M., Thornton, K. and Loaiza, J. (2013). "Coupling Reservoir and Well Completion Simulators for Intelligent Multi-Lateral Wells: Part-1" SPE-164815. Presented at EAGE Annual Conference \& Exhibition incorporating SPE Europec, London, UK, June 2013.

[18] Grubert, M. A. et al. (2009). "Coupled Completion and Reservoir Simulation Technology for Well Performance Optimization". SPE-12552. Presented at SPE Annual Technical Conference and Exhibition, New Orleans, USA. Oct 2009. 